Running head: Donation discussion message appeals

Developing persuasive message appeals to encourage young people to discuss their organ donation wishes with family

Melissa K. Hyde, ${ }^{1,2}$ Ioni M. Lewis, ${ }^{3}$ Katherine M. White, ${ }^{2}$ and Jane Shakespeare-Finch. ${ }^{2}$

${ }^{1}$ School of Psychology, The University of Queensland, Brisbane, QLD, Australia.

${ }^{2}$ School of Psychology and Counselling, and Institute of Health and Biomedical Innovation (IHBI), Queensland University of Technology, Brisbane, QLD, Australia.

${ }^{3}$ Centre for Accident Research and Road Safety - Queensland (CARRS-Q), Queensland University of Technology, and Institute of Health and Biomedical Innovation (IHBI), Brisbane, QLD, Australia.

Corresponding author: Dr Melissa Hyde, School of Psychology, McElwain Building, The University of Queensland, St Lucia, QLD, 4072, Australia. E-mail: m.hyde@uq.edu.au

Acknowledgements: This project was conducted while the first author was employed as a Vice Chancellor's Postdoctoral Research Fellow at Queensland University of Technology. We thank Kylie Wihardjo for assistance with data collection.

Funding statement: This study was supported by an Queensland University of Technology Institute of Health and Biomedical Innovation Early Career Researcher Grant to the first author.

Conflicts of interest: The authors have no conflicts of interest to declare. 


\title{
Developing persuasive message appeals to encourage young people to discuss their organ donation wishes with family
}

\begin{abstract}
Many young donors (i.e., young people who wish to donate organs upon death) are unaware of the need for family discussion to increase the likelihood of family consent for donation. They have low motivation to discuss and have not notified family of their wishes. We addressed a gap in existing research by developing and piloting six persuasive message appeals targeted specifically at young donors to encourage family discussion about donation. Young donors, who were Australian residents ( 7 females, 2 males) aged 21-25 years $(M=$ 23.00; $S D=1.73$ ), participated in qualitative interviews. Participants commented on their reactions to each message appeal, message effectiveness, and preferred appeals. Responses to message appeals were mixed. Mixed reactions were reflected in preferences for solely positive appeals or both positive and negative. Some participants felt negative emotional appeals were more impactful and memorable. Reactions to the provision of strategies to aid actual discussion (i.e., what to say, when to discuss, reminder prompts) in messages were guided by young donors' views of family discussion as either 'no big deal' or requiring preparation. Participants believed that including scenarios in which a person makes a donation decision for themselves or a loved one was thought provoking, motivating, and clearly conveyed the impact of the choice not to discuss on others. The four preferred message appeals included equal numbers of messages with positive and negative framing, high and low/no strategy, and individual vs. other perspective. Future piloting of these message appeals with a larger audience of young donors will determine message effectiveness in encouraging family discussion.
\end{abstract}

Keywords: organ donation, consent, communication, campaigns, young people 


\section{Introduction}

The mismatch between overwhelmingly positive attitudes toward organ donation and the increasing organ shortage means that few people will receive the therapeutic benefits of organ transplantation. For organ donation to proceed in countries with opt-in and soft opt-out systems such as the USA, UK, and Australia, family must authorize the donation of their loved one's organs even if an individual has previously registered his or her donation wishes (Rosenblum et al., 2012). Much research attests to the fact that when family know their loved one's wishes they are more likely to support them (DeJong et al., 1998; Siminoff, Gordon, Hewlett, \& Arnold, 2001). It is therefore critical for individuals to notify family of their donation wishes. Sharing donation wishes with family not only increases the likelihood of family respecting an individual's wishes, it reduces family distress, makes the individual aware of their family member's wishes, and increases individual confidence in and commitment to their organ donation decision (Hyde \& White, 2007, 2009; Jeffres, Carroll, Rubenking, \& Amschlinger, 2008). Despite these benefits many individuals, particularly young people, are not aware that they need to notify family of their wishes (DonateLife, 2010).

In Australia, young people aged 18 to 29 years, compared to other age groups, are the least likely to have discussed donation wishes with family and approximately half surveyed did not know that family consent is required for organ donation to proceed (Department of Health and Ageing, 2010). Young people cite a lack of motivation to engage in family discussion (Breitkopf, 2006; Hyde \& White, 2007) and associate discussion with barriers such as discomfort talking about the death of self and others, family opposing donation, uncertainty about how to raise the topic, having to justify their decision to family, creating distress or conflict if family disagree, and not having thought about or being ready to talk about it (Afifi et al., 2006; Breitkopf, 2006; Hyde \& White, 2007, 2009; McDonald et al., 2007; Radecki \& 
Jaccard, 1999; D. E. Vincent, 2006; Waldrop, Tamburlin, Thompson, \& Simon, 2004; Yeung, Kong, \& Lee, 2000).

It is surprising then that previous research has been limited in its use of interventions or persuasive message appeals to encourage family discussion (see Hyde \& White, 2012; Scott \& Quick, 2012). Prior research has focused largely on using persuasive messages to encourage target behaviours such as signing a donor card or registering consent on a donor register (e.g., Birkimer et al., 2006; Kopfman, Smith, Yun, \& Hodges, 1998; Siegel et al., 2008; Winkel, 1984). Furthermore, these studies include individuals who may be undecided about their donation wishes as well as those who wish to donate. It is likely that people who have already made the decision to be a donor may experience different motivational barriers to those who are undecided about their decision (Baughn, Rodrigue, \& Cornell, 2006; Hyde \& White, 2007). We extend this prior research by developing persuasive message appeals to encourage young people who have made the decision to be an organ donor (i.e., 'young donors') to communicate their donation wishes to family.

This study represents the second of three phases of a larger project. The first phase explored young donors' views on family discussion about organ donation and elicited their personal opinions about existing organ donation advertising/social marketing campaign materials (Authors names withheld, submitted). Based on key recommendations from the first phase and prior pilot work, we developed six written persuasive message appeals. These message appeals along with the corresponding recommendations for the first phase are presented in Table 1. For example, message appeal 1 drew on the finding and associated recommendation to emphasize the importance young people place on family discussion as a means to reduce the distress experienced by loved ones; message appeal 6 acknowledged that young people may differ in their approach to discussion ('no big deal' vs. in-depth preparation) and included a specific example of what to say to start family discussion (as 
opposed to other appeals which did not include a strategy). The six appeals were piloted in this phase using in-depth, qualitative interviews to elicit young donors' views on message effectiveness and ways in which these message appeals could be improved to suit the target audience.

\section{Method}

\section{Participants}

A convenience sample of nine young people attending or working at a university in Queensland, Australia participated in this study. We recruited participants who had a range of experience with communicating consent to offer insight into the extent to which the messages captured relevant aspects that helped young donors to discuss. Participants were Caucasian, predominantly female ( 7 females, 2 males), and aged between 21 and 25 years $\left(\mathrm{M}_{\text {age }}=23.00\right.$; $\left.\mathrm{SD}_{\text {age }}=1.73\right)$. Participants were not highly religious or spiritual $(\mathrm{M}=3.89 ; \mathrm{SD}=3.10$ on a 7point scale) and self-rated their knowledge of organ donation as average $(\mathrm{M}=3.89 ; \mathrm{SD}=1.62$ on a 7-point scale). All participants wanted to donate their organs upon death (i.e., young donors). Over half had communicated their consent for donation; one participant had joined the donor registry, three had discussed with family, and one had performed both behaviours. With regard to prior exposure to campaigns promoting family discussion of organ donation wishes, six participants had seen the Australian government's 'OK' campaign prior to participating in the study.

\section{Materials and Procedure}

Messages were developed to include content that matched the key recommendations from Phase 1 of the project (Table 1). In addition, messages were designed so that there were equal numbers of messages which: were framed either positively or negatively; included either low/no or high level of detail regarding strategies the individual could adopt to start family discussion; and depicted the individual as either making their own decision or having 
the decision made on their behalf. The main fictitious character, Taylor, featured in all messages. To enhance the possibility that young donors would relate to the central character we ensured there were no cues as to whether Taylor was male or female. The remaining two characters, parents John and Sue, featured in some of the messages also.

After receiving ethical approval from the institutional review board, young people were recruited via class websites, email, and snowballing to participate in a 1-hour interview in the later part of 2011. Participants were provided with an information sheet explaining the anonymous, confidential, and voluntary nature of their participation and gave their written and verbal consent to audio recording of interviews. Participants received an AUD\$20 music voucher to thank them for their time and contribution.

Table 2 lists the demographic and interview questions. At the start of the interview participants were informed that we were seeking their personal opinion about message appeals which had been designed to encourage young organ donors to talk about their organ donation wishes with family. Participants were instructed that these messages had made the 'final cut' and to keep in mind when they were reading each message that the ultimate aim was to convert the written content to audio-based messages similar to an advertisement they may hear on the radio. Participants were then presented with a series of six message appeals, the sequence of which was varied to minimise bias in responding or order effects. Message appeals are presented in Table 1. Initially, participants considered each individual message on its own merits. After each message, participants shared their first reaction to the message, identified aspects of the message they believed would help them to discuss their donation wishes, and aspects of the message they would change. To conclude, participants indicated their three preferred message appeals and justification for their preference.

\section{Data Analysis}


Interviews were transcribed verbatim and de-identified for data analysis. Seven interviews were conducted initially and thematic analysis of responses (Joffe \& Yardley, 2004) was used to identify recurring themes and exceptions in responses and to gain some consensus regarding young donors' reactions to messages and how each message could be improved. Some examples of suggested refinements included: the message was too long (message appeals 1, 4, and 5), the context was not realistic and should be changed (from a birthday to a barbecue for message appeal 3), there were too many tasks (e.g., whether to work through lunch or catch up with friends) that did not match the magnitude of the decision to donate organs (message appeal 2), and the context was too formal (changed from taking parents out for coffee to chatting over dinner for message appeal 6). Based on these responses, message appeals were refined further and then piloted with two additional participants to gauge reactions. Recruitment ceased when there was general consensus as to which messages were most effective and well-received (Table 3). For participant confidentiality, the findings are presented with supporting quotes citing only the participant's age and gender.

\section{Results}

\section{Initial reactions and effectiveness of message appeals in encouraging family discussion}

Message appeal 1 - What if you could do something to ease your parents' pain, even just a little - would you do it? Several participants commented that the use of emotion was a motivating factor that would encourage them to think about engaging family in discussion. They felt that the scenario described could actually happen and it was important to alleviate their parent's suffering. Participants also found the message to be motivating because it encouraged them to consider a different perspective, that of their parents or loved ones, that they may not have thought about before. 
"Seeing it from someone else's perspective, not just your choice but your choice influences how other people see it. But you wouldn't think about that usually of those sort of issues upsetting your parents later on, not knowing and not discussing. So I think it's quite effective in making you think about discussing it earlier so you don't cause even more pain for them". (Male, 24 years)

Others found the use of emotion to be too confronting or too negative (e.g. 'guilttripping', sad).

"I'd prefer something that was more positive and more about the help than really about 'oh because of your decision you've just caused more pain for your parents'. So it doesn't really have that sort of encouraging sort of message in it for me. The end just doesn't really encourage me. It sort of does make you think I should talk to someone...like talk to my family or loved ones about it but it's not really any encouraging me". (Male, 22 years)

One participant commented that the message assumed good family communication when this may not be the case and another believed that the message focussed on the parents too much and should be more about the young person in the story (Taylor) and what they wanted.

Message appeal 2 - Who makes your decisions? Several participants commented that this message appeal communicated the need for discussion clearly, succinctly and in a straightforward way. They thought that the context of everyday living and the positive framing of Taylor as a unique and independent person was something that Gen Y could relate to. Participants commented also that framing family discussion as a decision rather than as a morbid conversation would be helpful to encourage people who were comfortable notifying family. One participant commented that this message would motivate them to discuss their decision with family because it highlighted a discrepancy between the kind of person they were (someone in control of their life) and their behaviour (leaving a decision to someone 
else). Other participants felt the message challenged their assumption that their family would know what they wanted and that registering their decision was the only thing they needed to do.

"I think everyone, especially young people, like to be or at least feel like they are in control of their life. Especially round that sort of age because you know you've sort of flown the nest from your parents, but to know that you don't have that control... whereas you might just think 'Okay, I've registered, that's cool, that's fine' and then you read that it's like 'Well actually, maybe I should have that discussion'. I quite like that [message appeal]. That would encourage me to go and have a chat to my parents or whoever was closest to me" (Male, 22 years)

Despite the generally positive feedback, two participants reported that they did not connect with the message or did not get drawn into the story. Further, there was no guidance as to how to start family discussion and the importance of making the decision to talk to family was lost in the message. The following quote explains one participant's reaction.

“It [message appeal] talks about this person and it doesn't really feel like that's a message to me. It's just telling me a little story about somebody else. So I don't really care what your opinion is...but this Taylor person it says that um you know they make decisions and they don't like the idea of people making decisions for them. But you know that's not everybody and I probably wouldn't associate with that person" (Female, 22 years)

Message appeal 3 - Is it important to you to stand up for what you believe in? Young donors commented on positive aspects of this message appeal including that it outlined a good way to start the conversation and that portraying Taylor as spending time preparing for discussion would be helpful in normalising the process for others who needed to do the same. Participants also liked the inclusion of a positive family response to discussion; however, one participant commented that it may set the expectation that family conversation 
will be positive and this may be problematic for young donors whose parents do not accept their decision. The following comment is representative of participants' positive reactions to the message.

"I like that this sort of sets context because I think it sets the context that anyone would go through. So making the decision, having to think about how to have that conversation and what kind of goes into that decision and then what she wants to say. So I think it kind of steps it down really simply... and I think for lots of young people they would be able to go okay that's what you do" (Female, 25 years)

In spite of participants' positive views of the message, the majority response (just over half of young donors) was negative due to the perception that the message made a bigger deal out of family discussion than necessary ('it's not that shocking') or created an issue where there may not be one. One participant suggested also that by conveying the idea that discussion was something young donors should prepare for because their parents may have an issue with their decision may cause some young donors to choose not to discuss it to avoid any potential conflict. The following quote reflects participants' mixed perceptions of the message.

"I like the way it's going painting a nice positive scene...family event...everyone is there...they are having a chat... 'Hey Mum and Dad...I know it's a happy occasion, I just want to have a chat'... but it sounds like it is such a hard thing for Taylor. It sounds like she's almost stressing and worrying about just saying it. The message is right but Taylor should be coming across in more of a relaxed way like 'oh, now would be a good time to chat about it'. Not like 'oh my god should I chat about it now?!' I don't think that would be the right picture to portray...it should just be real casual and just not put so much emphasis on the pressure or the awkwardness of bringing it up in conversation" (Male, 22 years) 
Message appeal 4 - Have you made the memory? Although several participants commented that they found this message appeal to be intense and vivid and something that stayed in their minds, most commented that the appeal was too negative. Two aspects of the message were thought to be important and to help participants remember and be motivated to talk about their decision with their family; that organ donation was discussed but the opportunity to share a specific donation preference was not seized upon, and the assumption was challenged that even if family know the kind of person you are (in this case someone who enjoyed helping others) it does not mean they know your donation decision.

"I like the bit about how it was saying that she was the kind of person who enjoyed helping other people and I think it's more um relatable because I like helping people so it kind of makes me think well because I would like to I probably should [tell family]. If she can't make a decision...like the mum can't make a decision over already knowing her personality and what she's like then I probably should say something". (Female, 22 years)

Some young donors noted that the example of what to say and also the link to a situation that could be used to start a conversation (TV program) were helpful whereas others felt there needed to be more guidance included in the message about how to start the conversation.

"This is probably the message that makes you think about it most...makes me think heaps about the situation. If it happened to me, would my Mum react the same, and you know it's really easy to go and say 'hey Mum I want to donate my organs one day', but this does not give you the strategy to go and...If I saw a campaign that said 'Talk to your parents about this over dinner tonight' I would bring it up with them straight away because it's on my mind". (Female, 22 years)

In general, young donors felt that the story was realistic because it portrayed the difficulty of decision-making and was something they could imagine happening. Some 
participants felt that it was something they could relate to especially if they also liked to help others; however, other young donors believed that the message was more about the parent rather than the young person and questioned whether parents more so than young people would relate.

\section{Message appeal 5 - Do you consider yourself to be the responsible one in the}

family? All but one participant thought the change in perspective to asking a young person to make the decision for a family member was a scenario that was thought provoking, they could relate to and imagine themselves in, and would motivate them to discuss with family. One participant noted particularly that the message would encourage them to talk to as many people as they could, not just their parents. Several liked the acknowledgement of the conversation as potentially difficult to have or strange and believed that the idea of asking someone else whether they would like to donate rather than disclosing their own wishes might be an easier approach to family discussion.

"If I had read that or if I had listened to it on the radio I would go home and say 'Look, I listened to something on the radio that really kind of struck with me'...um ...yeah and I think I should talk about this right now rather than let it wait even though I know it's going to be uncomfortable. So I think having that being mentioned in here kind of helps because we all know it's going to be uncomfortable and at times we don't know how our parents are going to react so it's best to just get it over and done with so to speak'. (Female, 25 years)

Several participants commented also that an important aspect of the message was the emphasis on the young person never expecting to have to make a decision for someone else.

"I think it raises more questions and encourages a 19 year old to ask about that sort of stuff...cos it plays on the fact that you normally wouldn't think about it...and it's like when thinking about that oh it's like how would I feel if my Mum...would I know about hers... and I definitely don't know what my Mum would want" (Female, 22 years) 
Young donors' views on including a reference to a Facebook ad in the message were predominantly positive because they believed young people would relate to Facebook and that it would serve as a reminder or prompt for family discussion. However, some participants commented that nobody pays attention to ads on Facebook and that they were too small and not 'attention-grabbing'. One participant felt also that the fact that the young person was making a decision for their family and not just for themselves should be emphasised more to create a greater sense of responsibility in the young person.

\section{Message appeal 6 - How can you be prepared for the donor discussion?}

Participant reactions to this message appeal were mixed. Approximately half of the participants felt that the scenario described made 'too big a deal' out of family discussion. As one participant stated, "I never understood why people would think it would be a big deal to talk about donating their organs. Either you do or you don't' (Female, 22 years). In contrast, some participants liked that an effort was made to prepare for the discussion and the emphasis on discussing donation wishes as an important decision.

"I like the script for it that says 'I have some really important news' because it makes it important. Because I think that you have to say that it's really important because otherwise when push came to shove, if your family did not know that it was a super important decision to you they might not do it”. (Female, 21 years)

The script and Taylor's thoughts about how the conversation would unfold were well received by young donors who were apprehensive about family discussion. They thought including these elements was helpful and commented that while the script may not be exactly what they would say, it gave them ideas and could easily be adapted to suit their personal approach. Furthermore, some participants thought that including mention of family support for their decision and the young person having their wishes respected as an outcome of family discussion were positive aspects of the message. 
Two participants commented that the absence of an emotional aspect in the message meant that it did not motivate them, whereas others felt very motivated by the clear description in the message detailing how and when they could start a family discussion.

"I find this one really positive, like when I was reading it, it made me smile and that's a good way of getting it across. And then it says it doesn't have to be said over dinner and to make it suit your plans. I mean something like that it's not a casual issue but to bring it up casually, to discuss it and let them [family] know what your views are, that sounds like something I would do. That makes it really simple; reading it, it makes me embarrassed to realise that I haven't brought it up". (Female, 22 years)

\section{Preferred message appeals}

At the conclusion of each interview participants chose their three most preferred message appeals and described their reasons for their choice (Table 3). Overall, message appeal 2 and 4 were the most and least well received, respectively. Message appeals 6, 5, 1, and 3 were preferences also (ordered from most to least preferred). Due to both numbers 3 and 6 including the idea of preparing for family discussion and the latter being slightly more preferred by young donors, message appeal 6 only was retained. The following quotes summarise young donor's preferences.

"The reason why I liked number 1 was because it explains the situations so that people can really understand that this is the process. She's been in an accident, someone's going to come up to you, they're going to say 'do you want to donate her organs', and explain why even though she's registered...". (Female, 21 years)

"I like message 2 because it just feels like you are in control of your life...For me personally when I see that it's like oh yeah, you know I'm pretty busy but it's really important that I should go home and talk to my parents and talk to my partner and you know just have a 
quick chat in my day. So I like the way it comes across. It's not too heavy, it's not too dark. It's simple, it gets the point across". (Male, 22 years)

"Message appeal 5 the one where Taylor has to make the decision about her Mother's organs...that's tough. Although it's a bit negative I think that it could make people think twice about discussing their decision...I think it put it in context and the ad on Facebook thing that bit was pretty cool". (Female, 25 years)

"Number 6, I loved that one. I found it very easy, really simple to bring it up, and it will make me want to bring it up with my parents tonight. I will go home and talk to them". (Female, 22 years)

\section{Discussion}

To date, research has focussed on the development of message appeals to encourage individuals to register their donation wishes rather than engage in family discussion. However, research shows that family discussion is the behavior most likely to raise family awareness of loved ones' donation wishes and increase family consent for donation of loved one's organs (A. Vincent \& Logan, 2012). To address this gap we developed and elicited young donors' views on persuasive message appeals designed to encourage family discussion.

\section{Summary of key findings}

Overall, responses to most message appeals were mixed with the exception of message appeal 2 (Who makes your decisions?) where the response was overwhelmingly positive and message appeal 4 (Have you made the memory?) where the response was predominantly negative. Mixed reactions reflected some young donors' preference for solely positive messages compared to others who preferred messages that were framed positively but also recognised the value of a message that was framed negatively. These participants commented that it was the messages containing a negative emotional aspect, as compared to a 
positive appeal, that were most engaging and memorable and likely to encourage them to start a family discussion.

Mixed reactions were also a result of differences in young donors' confidence and comfort discussing donation and the reaction they anticipated from family (a difference that was evident in Phase 1 of the research also; see Authors names withheld., submitted). Young donors who expressed that family discussion was 'not that shocking' or 'no big deal' generally preferred the appeals that were positive and straightforward. In comparison, young donors who felt less confident in their ability to talk to family or expected their family would react negatively generally preferred the message appeals that supported the idea of preparation or provided strategies. Overall, inclusion of strategies in messages such as scripts detailing what to say, suggestions for situations in which to have a discussion, and prompts to remind young donors to discuss were well received. However, several young donors commented that they wanted more strategy built into the messages especially in cases where only one part of an overall strategy was included such as what to say or when to say it. Participants favoured relaxed, casual situations in which to have family discussion (e.g., a family barbecue or dinner) rather than situations that were more formal (e.g., a birthday party or over coffee).

Most participants found the change in perspective where either the parents were responsible for making a decision for their child Taylor or Taylor was responsible for making a decision for their parent as thought provoking and motivating. Young donors felt that these situations clearly conveyed the message that their choice to share their donation wishes (or not) impacted on others. Although there was individual variation in preferences, in general, participants found the scenarios presented to be realistic and something they could relate to and imagine themselves or others experiencing. Equal numbers of the final four preferred message appeals ( 1 - What if you could do something to ease your parents' pain...?, 2 - Who 
makes your decisions?, 5 - Do you consider yourself to be the responsible one in the family?, and 6 - How can you be prepared for the donor discussion?) reflected positive and negative framing, inclusion of high and low/no levels of strategy, and perspective taking of the individual making a decision for themselves or a loved one.

\section{Limitations of the study and conclusion}

Despite the strength of using qualitative research which offers an in-depth examination of the perspective of young donors in developing targeted persuasive message appeals to encourage family discussion, our use of a small convenience sample of predominantly female, Caucasian, highly educated young people who have already decided they wish to donate limits generalizability of the findings to young people in the broader community and to those who may be undecided about their donation preference. Our approach, however, is consistent with the majority of organ donation research with young people which has been conducted with university students, especially those enrolled in a psychology course of whom the majority are female. Furthermore, our target audience of young people represent a potential source of viable, healthy organs, because young people are more likely to have causes of mortality that increase their chances of eligibility for donation (e.g., road trauma). Our explicit focus only on young people who wish to donate is consistent with our aim to target young donors given the likelihood they may have different motivational barriers to family discussion compared to young people who are undecided or do not wish to donate.

We developed message appeals that were based on key findings from prior pilot work with this target audience. Consequently, although we attempted to include a range of scenarios that reflected different message framing (positive, negative), level of strategy to encourage efficacy (low/no, high), and perspective taking (individual making a decision for self or other), our messages did not cover all possible appeals that may be effective for young 
donors or for young people who are undecided about donation. Future piloting of these message appeals with a larger sample of young donors will determine whether these message appeals developed for and informed by young donors' views will be effective in motivating young donors to engage in family discussion; a behaviour critical to ensuring that young people's positive donation preferences translate into family consent for donation. 


\section{References}

Afifi, W. A., Morgan, S. E., Stephenson, M. T., Morse, C., Harrison, T. R., Reichert, T., \& Long, S. D. (2006). Examining the decision to talk with family about organ donation: Applying the theory of motivated information management. Communication Monographs, 73(2), 188-215.

Baughn, D., Rodrigue, J. R., \& Cornell, D. L. (2006). Intention to register as organ donors: A survey of adolescents. Progress in Transplantation, 16(3), 260-267.

Birkimer, J. C., Barbee, A. P., Francis, M. L., Berry, M. M., Deuser, P. S., \& Pope, J. R. (2006). Effects of refutational messages, thought provocation, and decision deadlines on signing to donate organs. Journal of Applied Social Psychology, 24(19), 17351761.

Breitkopf, C. R. (2006). Perceived consequences of communicating organ donation wishes: An analysis of beliefs about defending one's decision. Psychology and Health, 21(4), 481-497.

DeJong, W., Franz, H., Wolfe, S., Nathan, H., Payne, D., Reitsma, W., \& et al. (1998).

Requesting organ donation: An interview study of donor and nondonor families. American Journal of Critical Care, 7, 13-23.

Department of Health and Ageing. (2010). Media statement: Young people who believe in organ donation need to speak up now (Professor Jim Bishop). Department of Health and Ageing, Australian Government.

DonateLife. (2010). Let your family know your organ donation wishes - OK? Transplant Journal of Australasia, 19(2), 20.

Hyde, M. K., \& White, K. M. (2007). Young Australian adults' knowledge and beliefs about organ donation. Progress in Transplantation, 17(3), 220-227. 
Hyde, M. K., \& White, K. M. (2009). Communication prompts donation: Exploring the beliefs underlying registration and discussion of the organ donation decision. British Journal of Health Psychology, 14, 423-435.

Hyde, M. K., \& White, K. M. (2012). A test of three interventions to promote people's communication of their consent for organ donation. Psychology \& Health, doi: 10.1080/08870446.2012.731060.

Jeffres, L. W., Carroll, J. A., Rubenking, B. E., \& Amschlinger, J. (2008). Communication as a predictor of willingness to donate one's organs: An addition to the theory of reasoned action. Progress in Transplantation, 18(4), 257-262.

Joffe, H., \& Yardley, L. (2004). Content and thematic analysis. In D. F. Marks \& L. Yardley (Eds.), Research methods for clinical health psychology. (pp. 56-68). London: Sage.

Kopfman, J. E., Smith, S. W., Yun, J. K. A., \& Hodges, A. (1998). Affective and cognitive reactions to narrative versus statistical evidence organ donation messages. Journal of Applied Communication Research, 26(3), 279-300.

McDonald, D. D., Ferreri, R., Jin, C., Mendez, A., Smail, J., Balcom, P., . . Dibble, J. (2007). Willingness to communicate organ donation intention. Public Health Nursing, 24(2), 151-159.

Pomerantz, A. (2010). The value of qualitative studies of interpersonal conversations about health topics: A study of family discussions of organ donation and illustrations. In J. T. Siegel \& E. M. Alvaro (Eds.), Understanding Organ Donation: Applied Behavioral Science Perspectives. (pp. 272-291). West Sussex, United Kingdom: Wiley Blackwell. Radecki, C. M., \& Jaccard, J. (1999). Signing an organ donation letter: The prediction of behavior from behavioral intentions. Journal of Applied Social Psychology, 29(9), $1833-1853$. 
Rosenblum, A. M., Horvat, L. D., Siminoff, L. A., Prakash, V., Beitel, J., \& Garg, A. X. (2012). The authority of next-of-kin in explicit and presumed consent systems for deceased organ donation: An analysis of 54 nations. Nephrology Dialysis Transplantation, 27(6), 2533-2546.

Scott, A. M., \& Quick, B. L. (2012). Family communication patterns moderate the relationship between psychological reactance and willingness to talk about organ donation. Health Communication, 27(7), 702-711.

Siegel, J. T., Alvaro, E. M., Crano, W. D., Lac, A., Ting, S., \& Jones, S. P. (2008). A quasiexperimental investigation of message appeal variations on organ donor registration rates. Health Psychology, 27(2), 170-178.

Siminoff, L. A., Gordon, N., Hewlett, J., \& Arnold, R. M. (2001). Factors influencing families' consent for donation of solid organs for transplantation. JAMA: the journal of the American Medical Association, 286(1), 71-77.

Vincent, A., \& Logan, L. (2012). Consent for organ donation. British Journal of Anaesthesia, 108(S1), i80-i87.

Vincent, D. E. (2006). Exploring college students' family discussions about organ and tissue donation. Communication Research Reports, 23(4), 299-308.

Waldrop, D. P., Tamburlin, J. A., Thompson, S. J., \& Simon, M. (2004). Life and death decisions: Using school-based health education to facilitate family discussion about organ and tissue donation. Death Studies, 2004(28), 643-657.

Winkel, F. W. (1984). Public communication on donorcards: A comparison of persuasive styles. Social Science \& Medicine, 19(9), 957-963.

Yeung, I., Kong, S. H., \& Lee, J. (2000). Attitudes towards organ donation in Hong Kong. Social Science \& Medicine, 50, 1643-1654. 
Table 1

Revised final message appeals and links to phase 1 key recommendations

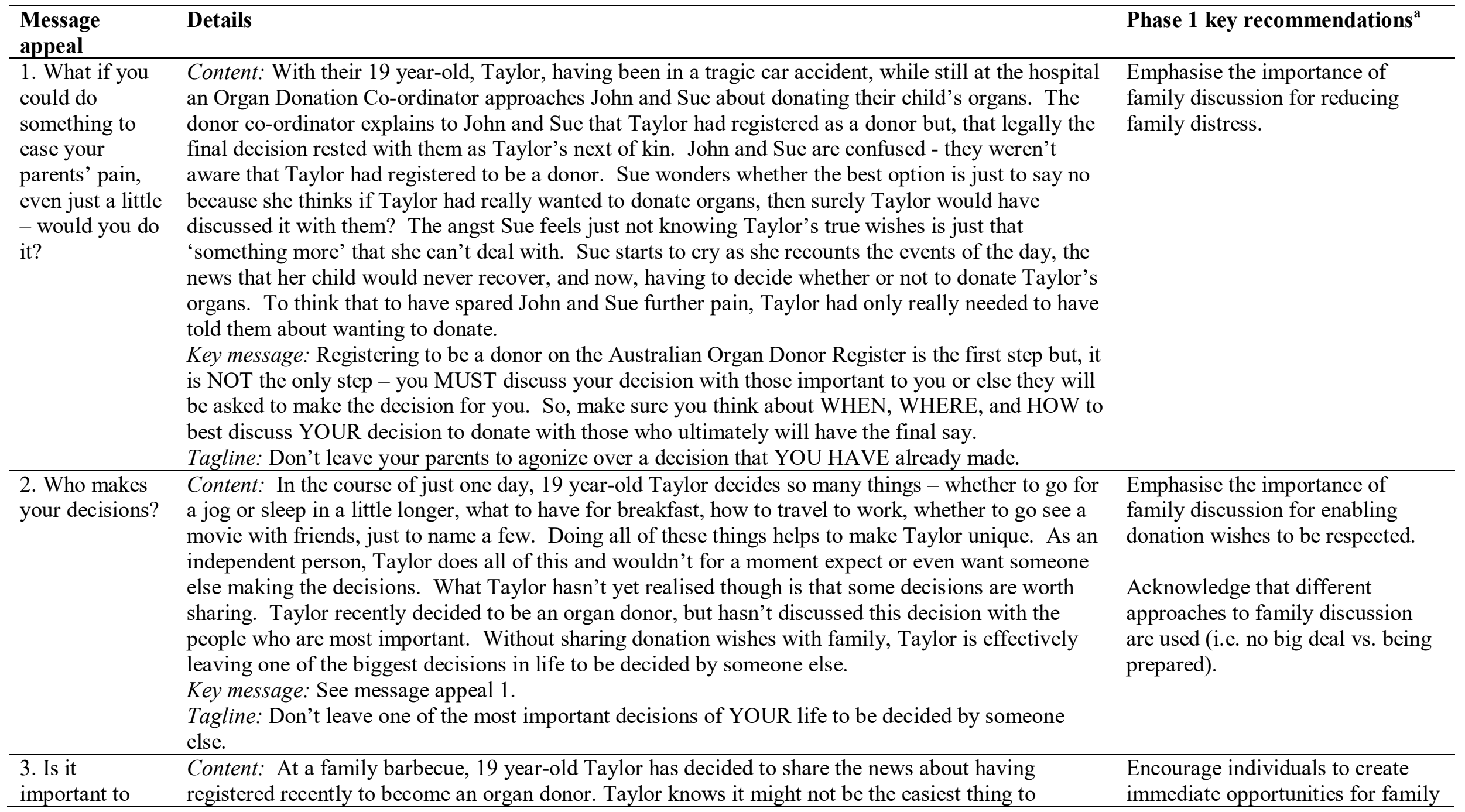




\begin{tabular}{|c|c|c|}
\hline $\begin{array}{l}\text { Message } \\
\text { appeal }\end{array}$ & Details & Phase 1 key recommendations ${ }^{\mathrm{a}}$ \\
\hline $\begin{array}{l}\text { you to stand up } \\
\text { for what you } \\
\text { believe in? }\end{array}$ & $\begin{array}{l}\text { discuss but has spent some time thinking about what to say to the family. Despite having registered to } \\
\text { donate, Taylor's next of kin will still have the final say about whether Taylor's organs are donated. } \\
\text { Taylor knows how important it is to discuss the decision to donate with family so that Taylor's wishes } \\
\text { will be supported if the need arises..."Hey Mum and Dad, I have something really important to tell } \\
\text { you while we are here altogether - yesterday, I registered to become an organ donor and I really need } \\
\text { you to know this so you can tell the Doctors for me if anything was to happen." While Taylor's } \\
\text { parents, John and Sue, are a bit surprised, they can see Taylor's dedication to the decision. Although } \\
\text { they don't even want to try imagining life without Taylor they cannot help but feel incredibly proud } \\
\text { of their child's generosity and compassion. } \\
\text { Key message: See message appeal 1. } \\
\text { Tagline: It doesn't have to be at a family barbecue, the most important thing is that you stand up for } \\
\text { what you believe in and discuss YOUR decision to donate with those who ultimately will have the } \\
\text { final say. }\end{array}$ & $\begin{array}{l}\text { Acknowledge that different } \\
\text { approaches to family discussion } \\
\text { are used (i.e. no big deal vs. being } \\
\text { prepared). } \\
\text { Include suggestions on what to say } \\
\text { to start and maintain positive } \\
\text { family discussion. }\end{array}$ \\
\hline $\begin{array}{l}\text { 4. Have you } \\
\text { made the } \\
\text { memory? }\end{array}$ & $\begin{array}{l}\text { Content: Sue has had a horrific day. Her } 19 \text { year-old child, Taylor, was in a tragic car accident and } \\
\text { the Doctors have told Sue that Taylor will not recover. The donor co-ordinator asks Sue if her child, } \\
\text { Taylor, may have ever considered donating organs upon death. The donor co-ordinator explains to } \\
\text { Sue that Taylor had not registered a decision about organ donation and that legally the final organ } \\
\text { donation decision rests with Sue, as Taylor's only next of kin. Sue struggles to recall if Taylor had } \\
\text { ever mentioned donating organs. Sue knows Taylor was the kind of person who enjoyed helping } \\
\text { others whenever possible... and there was one time in front of the television when Sue and Taylor had } \\
\text { talked about a TV program on organ donation...but Sue is just not sure what was said...if only she } \\
\text { could think straight... would Taylor really have wanted to donate? To think that Taylor had only really } \\
\text { needed to have taken that extra step and said, "Hey Mum, I think I would like to donate my organs } \\
\text { one day", and Sue would not be faced with this dilemma now. } \\
\text { Key message: See message appeal 1. } \\
\text { Tagline: Discuss YOUR donation decision with those who have the final say and make the memory } \\
\text { so that it's there if it's ever needed. Don't leave your loved ones to agonise over the decision. }\end{array}$ & $\begin{array}{l}\text { Emphasise the importance of } \\
\text { family discussion for reducing } \\
\text { family distress. } \\
\text { Include suggestions on what to say } \\
\text { to start and maintain positive } \\
\text { family discussion. } \\
\text { Recognise the need for reminders } \\
\text { and multiple prompts to encourage } \\
\text { discussion. }\end{array}$ \\
\hline $\begin{array}{l}\text { 5. Do you } \\
\text { consider } \\
\text { yourself to be } \\
\text { the responsible } \\
\text { one in the } \\
\text { family? }\end{array}$ & $\begin{array}{l}\text { Content: Taylor looks down at Mum in the hospital bed. Taylor recalls earlier in the day finding out } \\
\text { about the car accident, being told Mum would not recover, and agonizing over whether or not to } \\
\text { donate Mum's organs... a decision, that at } 19 \text { years of age, Taylor had to make all alone because there } \\
\text { was no other next of kin and Mum had never registered as an organ donor; A decision that Taylor had } \\
\text { never expected to have to make. Taylor's mind drifts recounting all the great conversations with } \\
\text { Mum about all kinds of things... except this... of course, it would have been a bit uncomfortable to }\end{array}$ & $\begin{array}{l}\text { Include stories that young people } \\
\text { can relate to as well as facts. } \\
\text { Emphasise the importance of } \\
\text { family discussion for reducing } \\
\text { family distress. }\end{array}$ \\
\hline
\end{tabular}




\section{Message \\ appeal}

\section{Details}

talk about organ donation but at least Taylor would have then known what decision to make instead of feeling guilty and wondering what was the right thing to do...wondering what Mum had really wanted. Why didn't they have that conversation? Only last week Taylor saw the page on Facebook about telling family your organ donation decision. Why didn't they have that conversation? It would have been so easy..."Hey Mum, I saw this page on Facebook today about needing to tell family your organ donation wishes. It said that we should really talk about our decision with family because they get the final say. It got me wondering what you think about organ donation, Mum? Do you want to donate?"

Key message: See message appeal 1.

Tagline: By you taking the initiative to discuss YOUR decision to donate with those important to you, you may be the one who gets all of the family talking about their wishes too.

6. How can you
be prepared for
the donor
discussion?

Content: 19 year-old Taylor has made the decision to share the news with Mum and Dad about wanting to be an organ donor. Taylor knows that it might be a little awkward, especially not knowing how Mum and Dad will react, but Taylor has read all the facts, and has spent some time thinking about what to say. Taylor has decided to chat to Mum and Dad over dinner and imagines how well this conversation will go..."Hey Mum and Dad, I have some really important news that I want to tell you while we are here together - I saw a TV program about organ donation and it got me thinking about it and I have decided that I would really like to register as an organ donor. I have been reading all about it and it says that I really need to tell you both so you can tell the Doctors for me if anything was to happen, and because ultimately you have the final say. I would really like your support." Taylor imagines that Mum and Dad will be a bit surprised by the news but will be happy to support Taylor's decision and will know that if they were ever to be asked to have the final say about donating Taylors' organs, they are making the 'right' decision to respect Taylors' wishes.

Key message: See message appeal 1.

Tagline: It doesn't have to be over dinner, just make YOUR PLAN to discuss YOUR decision in a way and at a time and place you feel comfortable.
Phase 1 key recommendations

Emphasise the importance of family discussion for enabling donation wishes to be respected

Include suggestions on what to say to start and maintain positive family discussion.

Encourage individuals to create immediate opportunities for family discussion.

Emphasise the importance of family discussion for enabling donation wishes to be respected.

Acknowledge that different approaches to family discussion are used (i.e. no big deal vs. being prepared).

Include suggestions on what to say to start and maintain positive family discussion.

Encourage individuals to create immediate opportunities for family discussion.

\footnotetext{
${ }^{\mathrm{a}}$ Key recommendations are based on Authors names withheld (submitted).
} 
Table 2

Interview questions

\begin{tabular}{ll}
\hline Construct & Questions \\
\hline Demographics & Sex (Male, Female) \\
Age (in years) & To what extent do you consider yourself to be a religious/spiritual person? $(0$ not at all to 7 a large extent $)$ \\
& Have you registered to be an organ donor on the Australian Organ Donor Register? (Yes, No) \\
& Have you previously discussed your decision to be an organ donor with a family member $($ Yes, No $)$ \\
& Overall, how would you rate your knowledge on the topic of organ donation $(1$ very poor to 7 excellent $)$ \\
& Have you previously seen a campaign in Australia about organ donation and/or communicating organ donation \\
& wishes? $($ Yes, No $)$. If yes, please give details about the campaign (free text response)
\end{tabular}

Reaction to message $\quad$ What was your first reaction when you read this message?

How did it make you think and feel?

\begin{tabular}{ll}
\hline Message strategies & Was there anything in the message that helped you think about how you might discuss your decision? \\
\hline Message refinement & If you were asked to assist in designing future messages, what would you change about this message? \\
& What part would you keep the same?
\end{tabular}

Message effectiveness Was there any particular message that stood out for you? Why?

Preferred messages If you could choose only 3 of the messages, which ones would you choose and why? 
Table 3

Preferred message appeals to encourage family discussion

\begin{tabular}{|c|c|c|c|c|}
\hline \multirow[b]{2}{*}{ Number } & \multirow[b]{2}{*}{ Message Appeal } & \multicolumn{3}{|c|}{ No. $(\%)$ of responses ${ }^{\mathrm{a}}$} \\
\hline & & $\begin{array}{l}\text { Overall } \\
(n=9)\end{array}$ & $\begin{array}{l}\text { Discussed with family } \\
\qquad(n=4)\end{array}$ & $\begin{array}{l}\text { Not Discussed with family } \\
\qquad(n=5)\end{array}$ \\
\hline 1 & $\begin{array}{l}\text { What if you could do something to ease your parents' pain, } \\
\text { even just a little - would you do it? }\end{array}$ & $4(14.8 \%)$ & $1(8.3 \%)$ & $3(20.0 \%)$ \\
\hline 2 & Who makes your decisions? & $7(25.9 \%)$ & $4(33.3 \%)$ & $3(20.0 \%)$ \\
\hline 3 & Is it important to you to stand up for what you believe in? & $4(14.8 \%)$ & $1(8.3 \%)$ & $3(20.0 \%)$ \\
\hline 5 & $\begin{array}{l}\text { Do you consider yourself to be the responsible one in the } \\
\text { family? }\end{array}$ & $5(18.5 \%)$ & $3(25.0 \%)$ & $2(13.3 \%)$ \\
\hline 6 & How can you be prepared for the donor discussion? & $5(18.5 \%)$ & $2(16.7 \%)$ & $3(20.0 \%)$ \\
\hline
\end{tabular}

${ }^{\mathrm{a}}$ Each participant chose 3 preferred message appeals 